\title{
A centralidade do cultural na cena contemporânea: evolução conceitual e mudanças sociais*
}

\section{RESUMO}

O objetivo desta comunicação é refletir sobre o sentido e as implicações do atual reordenamento das coordenadas do real a partir do axioma culturalista. O conceito de cultura sofreu várias transformações decorrentes do contínuo processo de negociação de seu status semiótico e epistêmico, seu valor social e seu alcance político e ideológico. Começamos com a base etimológica do termo, procedemos a uma leitura crítica do processo de sua politização e de culturalização da política, apontamos os limites de sua instrumentalização para, no final, propor uma nova conceituação mais condizente com o nosso momento histórico e as injunções de nosso enraizamento geográfico.

\section{PALAVRAS-CHAVE}

cultura

multiculturalismo

interculturalidade

\section{ABSTRACT}

The purpose of this communication is to reflect on the meaning and implications of the current redevelopment of the coordinates of the real from the axiom culturalist. The concept of culture has undergone many changes arising from the continuous process of negotiating its semiotic and epistemic status, their social value and its political and ideological power. We start with the basic etymology of the word, proceeded to a critical reading of the process of politicization and culturalization policy, point out the limits of their instrumentation to in the end, propose a new concept more consistent with our historical moment and the issue of our geographical roots.

\section{KEY WORDS}

culture

multiculturalism

interculturality

\section{Mohammed Elhajii}

Professor do Programa de Pós-Graduação em Comunicação da UFRJ/RJ/BR mohaiji@yahoo.com.br

\section{Sofia Zanforlin \\ Doutoranda do Programa de Pós-Graduação em Comunicação da UFRJ/RJ/BR sofiazanforlin@uol.com.br}

O objetivo desta comunicação é refletir sobre o sentido e as implicações do atual reordenamento das coordenadas do real a partir do axioma culturalista. Desde a primeira metáfora agrícola até a presente configuração global, o conceito de cultura sofreu várias transformações decorrentes do contínuo processo de negociação de seu status semiótico e epistêmico, seu valor social e seu alcance político e ideológico. A evolução do seu significado, todavia, corresponde a consideráveis mudanças na configuração de nosso real; o que torna a noção de cultura um espelho discursivo no qual se refletem os desejos, os medos e as disputas da sociedade.

Por isso, no quadro deste trabalho, tentamos apreender e analisar algumas das etapas de evolução do conceito e de seus desdobramentos sociais, políticos e subjetivos. Começamos com a base etimológica do termo, procedemos a uma leitura crítica do processo de sua politização e de culturalização da política, apontamos os limites de sua instrumentalização para, no final, propor uma nova conceituação mais condizente com o nosso momento histórico e as injunções de nosso enraizamento geográfico.

\section{As armadilhas do substantivo}

A consagração do prisma culturalista, enquanto principal lente de projeção de nosso real, constitui uma mudança radical em nossos paradigmas sociais, políticos e científicos. Equivale, segundo Bragança (2000), à configuração de um novo "universal", responsável pela recomposição de todas as nossas categorias mentais e redefinição de nossos modos de percepção, apreensão e interpretação da maioria das manifestações existenciais, sociais, políticas e subjetivas que nos cercam. Universalização, ou ainda "naturalização" da noção, que escamoteia a sua dimensão histórica e ativa seu potencial mitológico; conforme o princípio barthesiano de que "o mito transforma a história em natureza" (apud Bragança, 2000). Motivo pelo qual Wallerstein alerta aos estudiosos do tema sobre a necessidade de "assumir maior distância emocional em relação à cultura, encarar o próprio conceito [...] como objeto de estudo" (Wallerstein , 2004, p.148).

De fato, uma compreensão adequada do fenômeno requer tanto uma revisitação de sua base etimológica como o resgate de sua dimensão histórica e, principalmente, a explicitação do contexto sociopolítico no qual o conceito emergiu e tomou forma - ainda que, no espaço deste paper, não seria possível exaurir a questão. Assim, em que diz respeito ao primeiro nível desta indagação, vale lembrar que a noção de cultura afigura-se um exercício retórico longínquo que não dá mais conta da diver- 
sidade dos usos e aplicações que ela abarca hoje. Ligado, primeiramente, ao cultivo da lavoura, o termo "cultura" vira uma marca de distinção, passa a designar os assuntos do espírito e enquadrar o sujeito refinado ou "culto"; consolidando as então emergentes hierarquias sociais. Já, a partir do século XVIII, "cultura" começa a ser usada como sinônimo de "civilização", sinalizando um processo geral de progresso intelectual, espiritual e material e estreitando cada vez mais a relação entre as esferas de decisão, pensamento e gestão.

É mais recentemente, contudo, que "cultura" começou a sofrer um gradativo processo de "substancialização" e o culturalismo tomar a forma e a consistência sociopolítica que lhe conhecemos. Primeiro, as lutas pela independência, as descolonizações, os movimentos cívicos e os Estudos Culturais e de Gênero começaram a contestar o padrão civilizacional supostamente universal imposto pelo homem-branco-ocidental e disputar a fala ordenadora até então por ele monopolizada. O resultado foi (e continua sendo) uma formidável deflagração de narrativas, manifestações identitárias e padrões estéticos; dando voz e vez à periferia, aos grupos historicamente marginalizados, aos subalternos e aos discriminados e ostracizados de todo tipo.

Em seguida, os anos "Thatcher-Reagan" e a queda do muro de Berlim acabaram aniquilando por completo as veleidades políticas tradicionais e alertando sobre a vital urgência de inventarem-se novas ameaças e alteridades suscetíveis de manter o frágil equilíbrio de um mundo em transição (Rufin, 1991). Era preciso tanto repensar os projetos de sociedade vigentes, o sentido do EstadoNação e o lugar dos indivíduos e grupos no novo cenário, como resolver o dilema de um modelo civilizacional que sempre se autodefiniu por contraste e oposição ao Outro e que, de repente, se encontrava sem adversários capacitados nem concorrentes qualificados.

O correlato ideológico deste vazio existencial é conhecido: o decreto ad hoc do fim da História numa ponta e a proclamação ipso facto do choque de civilizações na outra - os dois termos da equação discursiva responsável pelo esvaziamento dos fatos, ações e relações sociais de seu teor histórico, sua naturalização, mitificação ou, ainda, estetização a-histórica. Pois, "a dominância da cultura, segundo Bragança, tem muito a ver com o "fim da história" e a transformação mítica do presente, por efeito da estética, da tecnologia, etc.", sublinhando que "a cultura é o modo atual de controlar o acontecimento". Já que, segundo o mesmo autor, "a cultura é, acima de tudo um modo de articular, de integrar e totalizar tudo o que existe em estado de dispersão [...] num momento em que o projeto historicista chegou ao fim, sem ter aparecido nenhum substituto à altura" (Bragança, 2000, p.19).

Appadurai (2004), por sua parte, denuncia a reificação do conceito de cultura; na medida em que a sua substancialização parece trazer de volta a cultura para o espaço discursivo da raça, justamente a idéia a ser combatida. O substantivo "cultura" parece privilegiar um certo tipo de compartilhamento, ligado a um diferencial de lifestyles, que desencoraja a atenção para visões de mundo e agencias de quem são marginalizados ou dominados.

O rearranjo conceitual, decorrente da conjuntura acima descrita, resultou num movimento político-organizacional em tripla hélice que veio ancorar o fenômeno da centralidade do cultural na cena contemporânea: de um lado, a politização da cultura e, por outro lado, a "culturalização" da economia e da política. A politização da cultura, fruto da invasão do centro da cena contemporânea por multidões de diferença ostentatória e de alteridade maciça, revogou solenemente a idéia de supremacia ocidental-branco-masculina e instituiu a diversidade (às vezes caótica) com norma social, política e estética. Além da formulação de políticas públicas de "reconhecimento" (Taylor, 1999) e a criação de centros e departamentos de estudos culturais e de gênero, a politização da cultura também se traduziu pelo uso das nomenclaturas identitárias e culturais como argumento histórico e referencial jurídico legal na disputa pelo poder simbólico.

Fenômeno, hoje, potencializado pelo fato "transcultural" enquanto traço constitutivo da realidade global, interligando os diferentes espaços culturais do mundo e favorecendo a multiplicação de fluxos e refluxos de grupos e indivíduos marcados por múltiplas identificações e acostumados a usar a cultura enquanto nova episteme global e como moeda de troca no mercado da diversidade. Segundo Yúdice (2004), ainda que haja na globalização uma inclinação à homogeneização, esse contexto seria responsável também pela forte propensão à diferenciação no interior das sociedades: "de fato, entre seus efeitos inesperados estão as formações subalternas e as tendências emergentes que escapam a seu controle, mas que ela tenta homogeneizar ou atrelar a seus propósitos mais amplos" (Yúdice, 2004, p.59). Já Hall (2003) aponta para a estratégia discursiva da globalização ao que ele denomina de "com-formação da diferença"; isto é, torná-la palatável aos olhares e gostos hegemônicos.

Paralelamente a essa recomposição do espaço simbólico, o fator cultural também vai passar a operar, devido ao desengajamento do Estado neoliberal, enquanto epicentro socioeconômico capaz de agregar habilidades e competências para capacitar os indivíduos ou adequálos às demandas do Mercado e prover algum bem-estar aos grupos. Estados e sociedades são impelidos a lançar mão da cultura e suas inúmeras derivações enquanto estratégia passível de alavancar a economia e estabelecer novos vínculos entre setores antes desconexos. A cultura vem adquirindo, assim, relevância e conveniência em torno de conceitos tais como "capital cultural" e "economia criativa" para integrar e subtender a nova gramática sociopolítica. Há, por exemplo, uma notável aproximação entre empresas privadas locais e transnacionais, entidades governamentais, representantes da sociedade civil e ONGs, tanto para subsidiar comunida- 
des locais ou a sociedade em geral como para otimizar seus recursos e incentivar o potencial criativo e o espírito inovador de seus agentes.

Assim, essa instrumentalização do cultural que adota um modelo quantitativo digno de um verdadeiro management empresarial, é praticada por uma multiplicidade de setores, que vão desde a indústria do entretenimento, pela realização de festivais de música, cinema e teatro, a projetos sociais que unem Estado, ONGs, e empresas privadas, na atuação junto a comunidades de baixa renda, envolvendo educação, esporte, patrimônio histórico, turismo, etc; no afã de gerar emprego e impulsionar o desenvolvimento local. Os ganhos obtidos por esses empreendimentos são avaliados a partir dos "incentivos fiscais, comercialização institucional ou valor publicitário, e a conversão de atividades não comerciais em comerciais" (Yúdice, 2004, p.40), além de um cruzamento desses indicadores com o retorno político e a interseção das agendas política e econômica, onde a cultura assume um papel ao mesmo tempo social, político e econômico.

A cultura, nesse contexto, terá se estabelecido como a própria lógica do capitalismo contemporâneo. "A cultura, compreendida não só afirmativamente, mas, ainda mais importante, como a diferença do grupo que consegue superar normas totalizadoras, tornou-se pedra de toque das reivindicações pelo reconhecimento e recursos" (Yúdice, 2004, p.87). Canclini conclui, a este propósito, que a "revisão dos vínculos entre Estado e sociedade não pode ser feita sem se levar em conta as novas condições culturais de rearticulação entre o público e o privado" (Canclini, 1995, p.24). Pois, a instrumentalização da cultura ou culturalização da economia amplia a agenda sociopolítica, incluindo a "economia cultural", segundo a qual, "explorar e celebrar as maneiras pelas quais a criatividade de todas as nações pode ser aproveitada para o desenvolvimento, a inclusão da diversidade e a coexistência pacífica" (Yúdice, 2004, p.35).

Já a culturalização da política, fruto do vazio ideológico causado pelo desmoronamento do modelo socialista, representa o que Wallerstein qualifica como o "lado negativo da geocultura" (Wallerstein, 2004, p.147) e ilustra, de modo trágico, os riscos da substancialização da cultura. Basta observar o quanto o cenário político mundial atual é marcado pela desconfiança acirrada do outro e o recolhimento patológico sobre si, para perceber que o discurso culturalista busca suas raízes nas narrativas escatológicas mais aterrorizantes e se nutre das fobias e paranóias mais arcaicas. Há, de fato, nesse processo de substancialização da cultura, um evidente retorno aos discursos demagógicos e populistas mais reacionárias por parte de segmentos cada vez maiores da sociedade, elegendo o medo e o horror ao outro em planos geopolíticos e em programas de governo.

Medo, desconfiança e desejo da aniquilação do outro e do diferente são, doravante, os princípios (a)morais e (a)éticos que movem as relações entre grupos, nações, estados, culturas e civilizações. A alteridade e a diferença ou são escamoteadas e negadas ou são excessivamente naturalizadas, essencializadas e investidas de uma aura negativa e demoníaca.

Em vez de acolher a diversidade cultural de nosso mundo, cujo conjunto polifônico constitui a civilização humana - ao exemplo do culturalismo antropológico humanista que forneceu a sua base conceitual ao antiracismo no pós-guerra (Balibar, 1988, p.33); o culturalismo político (ou política culturalizada) substitui a negação à negociação e a recusa à escuta do outro. Pois, sabemos que a matriz filosófica e o espelho teórico tanto das conhecidas ideologias de Estado como das narrativas deste novo culturalismo plantaram seu arcabouço conceitual, justamente, no campo da cultura substancializada que deturpou a tradição antropológica pluralista relativista, fascinada pela diferença e pelo mistério da diversidade humana, e a aprisionou nos etnocentrismos reducionistas e nos universalismos estreitos e suprematistas (Balibar; Wallerstein, 1988).

São essas estratégias discursivas que, segundo Appadurai (2004), acabam devolvendo a noção de cultura ao mesmo espaço semântico anteriormente ocupado pelo conceito de raça; ao qual ela veio em princípio combater. Na verdade, essa transfiguração do "culturalismo" em "neo-racismo" é um fenômeno já amplamente difundido na sociedade contemporânea. Ideologicamente, explica Balibar (1988), o racismo atual se inscreve no quadro de um "racismo sem raça" ou "racismo diferencialista". Uma forma de racismo cujo lema não é a hereditariedade biológica, mas a alegada irredutibilidade das diferenças culturais e a incompatibilidade das tradições ou cosmovisões.

"As explicações com base biológica perderam força desde que os nazistas levaram essas teorias à sua conclusão lógica. Mas não temam! Foi fácil substituir as explicações biológicas por explicações culturais", afirma Wallerstein (2004, p.142). Tática que se revelou mais perniciosa ainda, na medida em que, ao contrário da argumentação racialista caída em desuso, o culturalismo atual opera no registro dos clichês midiáticos e do senso comum e parece desfrutar de grande receptibilidade tanto junto ao público geral como nos meios políticos e acadêmicos. "Cultura", na verdade, se tornou um substituto de "raça" que justifica o ódio e a abominação do outro, e busca manter as mesmas estratégias discursivas de inferiorização, dominação e opressão de todos aqueles que, de alguma maneira, incomodam aos projetos hegemônicos mal acabados tanto das comunidades fechadas como das nações autocentradas.

\section{Os limites do instrumentalismo}

A principal manifestação da centralidade do cultural em nossa época é, com certeza, o surgimento do ideário multiculturalista e a sua difusão pelo mundo. Ao mesmo tempo sistema sociopolítico e perspectiva teórica, o multiculturalismo fundamenta seu discurso na necessi- 
dade de proporcionar a todos os grupos e comunidades de ordem étnica, cultural e / ou religiosa as mesmas chances e oportunidades de manter a sua memória "original" viva, cultivar a sua identidade, desenvolver seus próprios quadros de representação simbólica, prosperar socialmente e se expressar politicamente; pondo, assim, seus particularismos, suas crenças e suas características coletivas em oposição, disputa ou negociação contínua com os cânones e discursos hegemônicos da maioria da população ou do poder central.

O multiculturalismo, que adquiriu premência na pauta política e social, na Europa e América do Norte, a partir da Segunda Guerra, veio questionar a natureza presumidamente universal dos ideais iluministas, se contrapor ao modelo republicano supostamente igualitário, denunciar as injustiças políticas e sociais que se dissimulam atrás da fachada do democratismo burocrático e apontar o caráter profundamente heterogêneo da sociedade moderno-ocidental. Dentre outras conseqüências deste enfrentamento, pode-se destacar três grandes mudanças de atitude mental: Primeiro, a progressiva descrença nos mitos da alegada cidadania universal e a suposta neutralidade da Cultura - bandeiras do universalismo pós-iluminista que pregava a "cultura além das culturas", quando na verdade, não passava da defesa de um "particularismo que se universalizou com êxito e se tornou hegemônico em todo o globo" (Hall, 2003, p.77). Segundo, o desmonte da concepção republicana clássica do estado-nação; deixando evidente a sua realidade discursiva, narratológica e ideológica. Enfim, a inclusão da questão da diferença, seu valor, seu significado e seus limites nas discussões sobre a identidade nacional, a lealdade dos grupos e indivíduos e os imperativos de inserção social.

Também são três os fatores que contribuíram, segundo Hall (2003), para o fato que este debate se torne inevitável: o primeiro deles é relacionado ao fim do sistema imperial europeu e às lutas pela independência; daí a proximidade conceitual entre multiculturalismo e discurso pós-colonial - aspecto do qual tratamos na última parte deste trabalho. O segundo diz respeito ao fim da Guerra Fria, a partir do qual começou a se esboçar um processo de realinhamento de novas forças hegemônicas e consequente desmantelamento de antigas ordens para novos estados, notadamente daqueles alinhados à antiga União Soviética, conflagrando uma série de tensões culturais, religiosas e étnicas. O terceiro fator é associado à globalização e suas conseqüências, às formas transnacionais de produção e consumo, novas indústrias culturais e aos novos mercados financeiros.

Hall argumenta que sem o advento do multiculturalismo e a temática da diferença, proporcionados pela conjuntura acima aludida, seria difícil caminhar rumo a um quadro efetivo de pluralidade social. Assim, procurando "resgatar uma nova "lógica" política multicultural dos escombros dos vocabulários políticos [...], arruinados na erupção da própria questão multicultural"
(Hall, 2003, p.51), o co-fundador dos Estudos Culturais cita o exemplo da mudança de parâmetros decorrente da transferência dos termos da questão da raça para a etnia. Sendo a noção de "Raça" associada à aparência física, à herança genética e ao determinismo biológico e o racismo não nada mais de que "uma categoria discursiva que explica a diferença entre os povos no âmbito das distinções genéticas e biológicas". Enquanto "Etnia" pode ser um indicador de características ou práticas de ordem lingüística, cultural ou religiosa. Ou seja, se antes a problemática era tratada na perspectiva da biologia e na primazia de uma raça em desfavor de outras, hoje a reflexão se dá no campo da cultura e da religião.

O que não significa que seria o fim do estigma ou da discriminação das minorias e classes subalternas. Pelo contrário, como já frisamos na primeira parte deste texto, a simples mudança de nomenclatura técnica ou especializada não tem necessariamente um impacto considerável sobre as instâncias responsáveis pelas narrativas "alterofóbicas" ou "heterofóbicas" (Memmi, 1994); procedendo apenas a uma troca de tópicos discursivos sem real mudança de atitude. Hall (2003) concorda que essa troca não se traduz numa superação automática dos estereótipos ou uma real problematização do racismo; já que, "na maioria das vezes, os discursos da diferença biológica e cultural estão em jogo simultaneamente". Essas novas articulações acabam produzindo apenas a substituição ou a inclusão de elementos que geram os mesmos efeitos, na medida em que os discursos de inferiorização biológica e cultural repercutem o "momento multicultural" per se. Aliás, na verdade, tanto a reificação do molde cultural comunitário e a sua adscrição por fora, como a essencialização do projeto identitário e a construção de um Outro absoluto, qual for a adjetivação empregada e a metáfora escolhida, não passam de estratégias discursivas de sua sujeição e / ou exclusão.

Além dessas dificuldades conceituais, o multiculturalismo também é cobrado em termos práticos de eficiência e operacionalidade no que tange a questões urgentes tais como a delimitação dos contornos de cada comunidade ou cultura, a aplicabilidade abstrata de seus princípios a todos os tipos de comunidades (indígenas, étnicas, nacionais, linguísticas, de imigrantes, etc.), a natureza das relações entre os diferentes grupos componentes da paisagem multicultural e para com a sociedade geral, a lealdade e as possibilidades de escolha do indivíduo entre coerção simbólica comunitária e normatividade abstrata nacional, etc. De fato, um dos reproches feitos ao multiculturalismo é o seu suposto antiindividualismo, em função de seu imperativo incondicional a favor da primazia da totalidade (comunidade) em detrimento da parte (indivíduo). Contestando, deste modo, o ideal republicano da liberdade do sujeito em escolher suas filiações sociais e afetivas, e tornando o pertencimento à comunidade cultural uma fatalidade inegociável. 
Vale observar, todavia, que existem, na teoria política liberal, abordagens em total sintonia com a perspectiva multiculturalista, que defendem a idéia de uma cidadania multicultural compatível com as normas políticas e filosóficas que regem as democracias liberais; tais como unidade nacional, justiça social e liberdade individual. Com relação a este último ponto, Kymlicka (2001) chega até a inverter a equação e sustentar que, no atual "contexto multicultural de fato", só seria possível respeitar a liberdade individual, se antes, permitir a cada um gozar do direito de cultivar e manifestar seus pertencimentos culturais, lingüísticos, étnicos ou confessionais.

Como se pode constatar, o debate em torno do multiculturalismo repercute uma série de contradições presentes na acepção da noção desde as suas primeiras formulações e que continuam sem resposta final e definitiva. Outros aspectos do multiculturalismo desapontam pelo instrumentalismo da noção de cultura, o excessivo formalismo das relações sociais e o exageradamente rígido sentido de pertencimento. Assim, além do evidente risco de reduzir a sociedade a uma mera justaposição de grupos distintos, Cogo, por exemplo, destaca o "perigo de que as culturas se encerrem em particularismos incomunicáveis, a partir da identificação e avaliação dos indivíduos exclusivamente pelo pertencimento a uma única comunidade" (Cogo, 2001, p.17).

Insatisfação compartilhada por Bauman que teme o aprofundamento da atual tendência à pulverização dos grupos sociais; o que tornaria mais difícil ainda "um diálogo entre culturas, única ação que poderia superar a atual incapacidade dos potencias agentes políticos da mudança social" (Bauman, 2003, p.97). Sem esquecer que o fechamento dessas comunidades e a edificação de sua identidade cultural em cima de discursos étnicos ou religiosos simplistas, além as tornarem mais vulneráveis a todo tipo de manipulação, só reforça seu isolamento e sua marginalização.

Fatores que, numa perspectiva ideológica crítica, reforçam mais ainda a preocupação com as conseqüências da mercantilização da diferença e da alteridade, sua instrumentalização e seu esvaziamento político. Zizek (2004), no caso, considera que a luta pelo reconhecimento identitário e cultural, como fim em si ou como meio de mobilização econômica, contribui para desqualificar ou obstruir o debate sobre as relações de dominação e as verdadeiras causas de injustiça social e falência política. Pois, é verdade que paira sobre o multiculturalismo certa suspeita de sua cooptação, reapropriação ou recuperação por parte do establishment e o uso de seu discurso militante como antídoto anestesiante contra o velho projeto esquerdista movido pelas utopias de igualdade, justiça social, luta de classe e outros temas de contestação social, hoje considerados ultrapassados e pouco glamourosos.

Ou seja, a roupagem emancipatória ostentada pelos defensores das diferenças culturais e identitárias, muitas vezes, não passaria de estratégia discursiva ou re- curso retórico a favor da manutenção do status quo econômico e social. A questão passa a ser, portanto, como equacionar o cultural ao político. Pois, o debate sobre os possíveis caminhos do multiculturalismo abunda em controvérsias em torno de questões políticas e ideológicas como cidadania, inclusão social e bem-estar. Ainda mais no momento em que a culturalização da política passa a designar quadros hierárquicos entre comunidades e nações, e servir a deferir para o cultural problemas fundamentalmente políticos, tais como elegibilidade, disputas por terras, recursos naturais, habitação e empregos.

Assim, na tentativa de fugir dessas zonas movediças da multiculturalidade, alguns autores procuram re-significar o conceito e re-problematizar seu sentido. Kellner (2001), notadamente, propõe a adoção de uma linha de "multiculturalismo crítico", onde o foco estaria voltado para a análise das relações de dominação e opressão, do modo de funcionamento dos estereótipos e da resistência dos grupos estigmatizados a representações dominantes.

\section{A principal manifestação da centralidade do cultural em nossa época é, com certeza, 0 surgimento do ideário multiculturalista e a sua difusão pelo mundo.}

Shohat e Stam (2006), por sua parte, advogam um multiculturalismo sem formato engessado e definitivo um tipo de plataforma conceitual que oriente as discussões sociais, políticas e propriamente culturais, no sentido de incentivar uma reestruturação e uma re-conceitualização dos termos das relações de poder. Além disso, eles elegem a noção de multiculturalismo policêntrico ou radical no sentido de que questões relacionadas à identidade ou diversidade cultural devem ser discutidas de maneira integrada às comunidades, sociedades e nações, pois elas não existem de modo autônomo, "mas numa teia densa de relações" (Shohat; Stam, 2006, p.86). Sendo, portanto, a perspectiva dialógica e plural uma estratégia anti-segregacionista e contrária à versão liberal, geradora das políticas "estratificantes".

Destacam os mesmos autores as possibilidades enriquecedoras do multiculturalismo em sua versão policêntrica, uma vez que ao enxergar as identidades como "múltiplas, instáveis situadas historicamente, produtos de diferenciações contínuas e identificações polimórficas", abrir-se-ia caminho para construções baseadas mais 
em identidades e desejos de políticas comuns: “O policentrismo é, portanto, recíproco e dialógico, vê todo ato de troca verbal ou cultural como algo que acontece entre indivíduos e comunidades permeáveis e mutáveis" (Shohat; Stam, 2006, p.88). Esse caminho, além de apontar para a reestruturação e re-significação de relações intercomunitárias no interior e "para além do estado-nação", implicaria numa sintonia com as novas perspectivas sinalizadas pelos desdobramentos do âmbito das relações globais em que "o mundo possui diversos centros culturais dinâmicos" e a ampliação de possibilidades de trocas, baseado em reciprocidades e dialogismo.

\section{A busca por novos horizontes}

O conjunto dessas inquietações, aqui brevemente apresentadas, acaba refletindo a urgência de reexaminar o fenômeno da centralidade da cultura na cena contemporânea à luz de novos indicadores e em função de novos parâmetros socio-históricos. Assim, seria oportuno retomar, primeiro, a questão da proximidade conceitual entre multiculturalismo e discurso pós-colonial vislumbrada na segunda parte deste artigo.

De fato, o contexto pós-colonial trouxe à tona discussões sobre as novas formas de pertencimento e as novas acepções das noções de etnicidade, cultura, política e religião, nos múltiplos cenários de dominação colonial e suas consequientes situações de diferença, alteridade e / ou subalternidade. Ao mesmo tempo em que instigou um movimento cataclísmico de questionamento e contestação do discurso eurocêntrico de estirpe colonialista sobre o Outro, notadamente com o "Orientalismo" de Said (1990), a teoria pós-colonial também sempre se mostrou atenta à multiplicidade das vozes do Ocidente e a seu potencial revolucionário e emancipador.

Por outro lado, principalmente na obra de seus protagonistas mais novos (Ahmad, Appiah e outros), o póscolonial combateu firmemente todo radicalismo identitário, culturalista ou nacionalista. Além de deixar claro que não existem divisas identitárias ou culturais estancas e definitivas entre grupos sociais ou humanos, ele ainda adotou paradigmas lingüísticos e literários para explicitar a natureza narrativa e discursiva de todo projeto identitário. Memória, história, passado e origens dos grupos ou nações são, para a teoria pós-colonial, narrativas, (re) invenções e / ou (re) escritas produtos das coordenadas conjunturais do presente, movidas por fatores, projetos e objetivos políticos, ideológicos e sociais atuais a atuantes. Ou seja, todo texto histórico e todo memória identitária cultural, religiosa ou étnicas são, na verdade, um perspectiva do presente sobre o passado assim (re) inventado e instrumentalizado para a conquista de posições políticas e a disputa de poder simbólico.

Porém, o pós-colonial que foi impulsionado pela perspectiva pós-estruturalista e constituiu um grande passo na busca por uma nova abordagem sociopolítica da questão identitária, étnica e cultural, também foi objeto de algumas críticas. Principalmente por apagar algumas "relações de perspectiva", no sentido de não deixar claro se o "pós" indicaria a perspectiva do ex-colonizado ou do colonizador, como também excluiria países que apesar de formalmente separados da metrópole há séculos (as Américas em particular) ainda lidam com a "distribuição desigual de recursos e poder no mundo".

A questão que se impôs, portanto, é: "Quando, então, começa o pós-colonial, e quais são as relações entre esses diversos inícios?" (Shohat; Stam, 2006, p.76). A resposta é que o discurso pós-colonial é de grande pertinência quando se trata de apreender a questão identitária cultural na sua totalidade abstrata, mas à medida que se tenta focar um recorte sócio-histórico específico, acaba se revelando bastante limitado, esquemático e parcial. O grande mérito do discurso pós-colonial, todavia, foi de incluir na pauta político-cultural as noções de "creolização" (Glissant, 1981) e "hibridismo", abrindo espaço para uma nova lógica acerca dos processos culturais; sendo que hibridismo não se refere apenas a indivíduos "híbridos" que podem ser contrastados com "os tradicionais e modernos como sujeitos plenamente formados", mas sim de "um processo de tradução cultural. [...] Em suas muitas variantes, a 'tradição' e a 'tradução' são combinados de diversas formas” (Hall, 2003, p.74).

Daí o interesse pela proposta intercultural, sem dúvida, mais adequada à realidade histórica, social, política e econômica da América Latina; conforme já temos concluído em trabalhos anteriores, ao buscar compreender os fenômenos sociais e culturais a partir de um corpo teórico que ressalte nossas peculiaridades históricas, o contexto global atual e a base midiática e tecnológica responsável pela reformulação de nosso imaginário. Pois, como afirma Canclini, "As transformações recentes fazem tremer a arquitetura da multiculturalidade"; já que os quadros simbólicos "que ordenavam a coexistência de grupos em territórios delimitados são insuficientes ante a expansão das misturas interculturais" (Canclini, 2004, p.16).

Astrain (2003), por sua parte, defende que a noção de interculturalidade é conseqüência das recentes formulações teóricas (ao exemplo do pós-colonialismo) que apontam as culturas enquanto sistemas dinâmicos no que diz respeito à sua capacidade de tradução da diferença e de contínua reinterpretação de suas próprias tradições; permitindo o surgimento de novas categorias discursivas e mentais, tais como hibridismo e "retnificação". O que, segundo o mesmo autor, é de grande valia para a análise e compreensão das modernas sociedades latinoamericanas, caracterizadas por sua crescente heterogeneidade social e humana e a diversidade de suas formas de organização comunitária e manifestação identitária.

Canclini também recorre à noção de interculturalidade, como uma alternativa à despolitização do multiculturalismo e sua inclinação segregadora, no sentido que o conceito de interculturalidade traz em sua significa- 
ção a idéia de troca, negociação dos limites de convivência entre diferentes, lutas pelos direitos políticos, cidadania e representação; remetendo à confrontação social e ao entrelaçamento simbólico. Enquanto "multiculturalidade supõe aceitação do heterogêneo; interculturalidade implica que os diferentes são o que são, em relações de negociação, conflito e empréstimos recíprocos" (Canclini, 2005, p.17).

Ele aponta, assim, para o surgimento de uma nova nomenclatura que se traduziria numa forma inédita de atuação sobre as políticas sociais, atualizando o debate em torno das noções de inclusão num mundo cada vez mais dependente de conexões e interseções. Dessa for$\mathrm{ma}$, a proposta intercultural apreende o mundo enquanto um conjunto de "hegemonias dispersas" (Appadurai, 2004) e pensa as sociedades a partir da mudança de "problemática da diferença e da desigualdade para inclusão/ exclusão", num contexto onde os indivíduos estão inseridos numa lógica muito mais fluida de pertencimentos diversos.

Appadurai consagra as migrações e as mídias, sobretudo as eletrônicas, como os dois expoentes caracterizadores da contemporaneidade. Nesse cenário, se tomado como pressuposto, a interculturalidade surge como amparo fundamental para a negociação de pertencimentos de cidadãos cada vez mais globais, que possuem, ainda assim, todo um histórico pessoal identitário impossível de ser apagado em favor de alguma nova ou única identidade. O intercultural como possibilidade de comunicação entre diferentes assume a cultura como ponte para um diálogo nem sempre fluido, muitas vezes conflitante, porém, apoiado sob uma base de negociação constante e imprescindível. Qualquer coisa fora disso, torna-se imposição, ou sobreposição de uma expressão em detrimento de outras.

De fato, o intercultural não veio reivindicar o direito à diferença, mas parte dela como um dado inexorável da realidade global. Não surge também imbuído do ideal de recuperação das utopias humanistas que habitam o arcabouço de intenções do multiculturalismo, no entanto, reclama a aplicabilidade de seus princípios a todos os tipos de comunidades (indígenas, étnicas, nacionais, lingüísticas, de imigrantes, etc.), aos diferentes grupos componentes da paisagem multicultural e para com a sociedade geral, o direito de cultivar e manifestar seus diversos e plurais pertencimentos culturais, lingüísticos, étnicos ou confessionais.

Sendo assim, a proposta intercultural consagra a centralidade do cultural na lógica contemporânea, porém, reclama a efetivação política da ampliação e da inclusão, do acesso e do direito à conexão e à mobilidade com condições para o exercício da plena cidadania, ciente, portanto, das disputas de poder que são travadas ao longo desse caminho. A proposta intercultural se distingue do culturalismo político (Balibar, 1988) uma vez que presume a tensão e a negociação como elemento ativo da realidade social contemporânea e parte dos questiona- mentos e críticas que examinam as limitações e contradições internas do multiculturalismo, ao ressaltar que se deve tomar todo o cuidado para não incorrer em novas formas de fechamento étnico ou inversão de parâmetros sociais e políticos que também acabam produzindo injustiças e discriminações.

É nesse sentido que se faz necessário o estabelecimento de outro tipo de solidariedade e identificações onde os mais variados discursos possam coexistir com as mais diversas relações, constituindo o sujeito como o local de competição de diferentes discursos e vozes. A questão passa, portanto, como pensar os processos de inclusão, conexão e mobilidade junto ao direito de manifestação à diferença num contexto de globalização, transnacionalidade e transculturalidade.

Transculturalidade, o mais recente desdobramento da centralidade do cultural na cena contemporânea, deve ser entendida como o conjunto de processos simbólicos que possibilitam o compartilhamento de produtos e espaços culturais globais e neles fixarem seus referenciais identitários e mapas subjetivos provisórios ou permanentes. Trata-se, portanto, de uma situação "pós-estadonacional" inerente à realidade social e política que caracteriza o mundo contemporâneo, marcado pela inequação estrutural entre os planos nacional-estatal e cultural-identitário. Ou seja, o fenômeno diz respeito aos modos de organização e ação dos grupos sociais e comunidades humanas inseridos em mais de um quadro social e / ou nacional estatal, tendo referenciais culturais, territoriais e/ ou lingüísticos plurais, e conectados através de redes sociais transnacionais que garantem algum grau de identificação além das fronteiras formais de seus paises ou regiões.

\section{Considerações finais}

Não pretendemos, no espaço do presente trabalho, aprofundar a nossa análise a propósito desta problemática. Queríamos, apenas, aproveitar a sua composição social, política, cultural e, principalmente, tecnológica para desvelar o desenho midiática comunicacional deste nosso percurso reflexivo.

De fato, podemos afirmar que a realidade transcultural só pôde emergir em função da atual configuração atual da esfera pública e na concretude de sua nova economia política das comunicações. A importâncias das NTICs (Novas Tecnologias de Informação e Comunicação) para a conformação de construtos identitários transculturais equivale, hoje, ao papel do "Capitalismo Editorial" (referido por Deutsch, Anderson e outros) na consolidação dos imaginários nacionais. Pois, paralelamente à sua estruturação organizacional em redes de redes, o presente cenário global, sustentado pelas NTICs, favorece a multiplicidade de sensibilidades e subjetividades que desconhecem a continuidade física do terreno social e prescindem de uma ancoragem exclusiva no território efetivo ou no mapa estatal oficial.

Podemos, assim, concluir que, além do fato da cultura 
ser um espaço e objeto de trocas discursivas e comunicacionais, o multiculturalismo corresponde a uma distribuição comunitária da paisagem midiática nacional, a interculturalidade às possibilidades de troca, empréstimo e tradução entre grupos já não mais estanques ou herméticos, enquanto a transculturalidade equivaleria ao plano simbólico cultural de nossa realidade global, em rede e irreversivelmente marcada pelo substrato midiático transnacional FAMECos

\section{NOTAS}

* Texto apresentado na Compós 2009 no GT Comunicação e Cultura

\section{REFERÊNCIAS}

ANDERSON, Benedict. Comunidades Imaginadas. São Paulo: Companhia das Letras, 2008.

APPADURAI, Arjun. Dimensões Culturais da Globalização. Lisboa: Editorial Teorema, 2004.

ASTRAIN, Ricardo Salas. Ética intercultural e Pensamento Latino-Americano. In: SIDEKUM, Antonio (Org.). Alteridade e multiculturalismo. Ijuí: Unijuí, 2003.

BALIBAR, Etienne; WALLERSTEIN, Immanuel. Race, Nation, Classe: Les Identités Ambigues. Paris: La Découverte, 1988

BAUMAN, Zygmunt. Comunidade. RJ: Zahar, 2003.

BHABHA, Homi K. O Local da Cultura. Belo Horizonte: Editora UFMG, 1998.

BRAGANÇA DE MIRANDA, José A. A Cultura como Problema. Revista de Comunicação e Linguagem, Lisboa, n. 28, out. 2000.

CANCLINI, Néstor García. Culturas Híbridas. São Paulo: EDUSP, 2004.

Diferentes, Desiguais e Desconectados: Mapas da Interculturalidade. Rio de Janeiro: Editora UFRJ, 2005.

CASTELLS, Manuel. O Poder da Identidade. São Paulo: Paz e Terra, 2000.

COSTA, Sérgio. Dois Atlânticos: Teoria Social, Anti-Racismo, Cosmopolitismo. Belo Horizonte: Editora UFMG, 2006.

ELHAJJI, Mohammed. Comunicação, Cultura e Conflitos: Uma Abordagem Conceitual. In: PAIVA, Raquel; BARBALHO, Alexandre. (Org.). Comunicação e Cultura das Minorias. São Paulo: Paulus, 2005.
GLISSANT, Edouard. Le Discours Antillais. Paris: LESEUIL, 1981.

HALL, Stuart. Da Diáspora: Identidades e Mediações Culturais. Liv Sovik (Org.). Belo Horizonte: Editora UFMG, 2003.

KYMLICKA, Will. La Citoyenneté Multiculturelle: Une Théorie Libérale des Droits des Minorités. Paris : La Découverte, 2001.

MEMMI, Albert. Le Racisme. Paris: Folio, 1994.

RUFIN, Jean.Christophe. L'Empire et les Nouvau Barbares. Paris: Lattès, 2001.

SAID, Edward. Orientalismo: o Oriente como Invenção do Ocidente. São Paulo: Companhia das Letras, 1990.

SEMPRINI, Andrea. Multiculturalismo. Bauru: Edusc, 1999.

SHOHAT, Ella; STAM, Robert. Crítica da Imagem Eurocêntrica. São Paulo: Cosac Naify, 2006.

WALLERSTEIN, I. O Declínio do Poder Americano. Rio de Janeiro: Contaponto, 2004.

YÚDICE, George. A Conveniência da Cultura: Usos da Cultura na Era Global. Belo Horizonte: Editora UFMG, 2004.

ZIZEK, Slavoj. Bem-vindo ao Deserto do Real!: Cinco Ensaios sobre o 11 de Setembro e Datas Relacionadas. São Paulo: Boitempo Editorial, 2003. 